\title{
Effects of dietary essential fatty acids on reproduction rates of a subtropical calanoid copepod, Acartia erythraea
}

\author{
Mianrun Chen ${ }^{1}$, Hongbin Liu ${ }^{1, *}$, Bingzhang Chen ${ }^{2}$ \\ ${ }^{1}$ Division of Life Science, The Hong Kong University of Science and Technology, Clear Water Bay, Hong Kong SAR \\ ${ }^{2}$ State Key Lab of Marine Environmental Science, Xiamen University, Xiamen, PR China
}

\begin{abstract}
To understand the role of food quality in planktonic trophic interactions and marine copepod reproduction, we conducted laboratory experiments to investigate the effect of different prey with specific fatty acid profiles on the reproduction of Acartia erythraea. Copepod egg production rates and hatching success were assessed using a mixed diet combining Dunaliella sp. (containing no long-chain polyunsaturated fatty acids, PUFAs) with the diatom Thalassiosira weissflogii (high eicosapentaenoic acid, EPA), the dinoflagellate Prorocentrum dentatum (high docosahexaenoic acid, DHA), the cryptophyte Rhodomonas sp. (moderate EPA and DHA) or the ciliate Strombidium sulcatum (high nitrogen), respectively. Copepods fed a mono-diet of Dunaliella sp. were used as controls. The results showed that a food mixture with dinoflagellates provided the highest egg production rate and hatching success. The bacterivorous ciliate was not a good prey for copepod reproduction because of the deficit in fatty acid composition, despite its low C:N ratio. Generalized additive models indicated that food quality (ingested PUFAs) was important for egg production in addition to food quantity. Among PUFAs, DHA was the most important specific fatty acid based on its high partial correlation coefficient for egg production rate. Egg hatching success was significantly correlated with the percentage of the 3 major $\omega 3$ unsaturated fatty acids (alpha-linolenic acid ALA, EPA and DHA) in diets.
\end{abstract}

KEY WORDS: Food quality - Essential fatty acids · DHA · EPA · Copepods · Acartia $\cdot$ Egg production rate $\cdot$ Egg hatching

\section{INTRODUCTION}

Reproductive success of copepods depends on the nutritional condition of females, which in turn is influenced by food quality (Jónasdóttir 1994, Guisande et al. 2000). The effect of food quality is particularly marked in environments where food is abundant but particular elements or chemical components are lacking (Anderson \& Hessen 1995, Ederington et al. 1995, Kleppel et al. 1998). To optimize the nutritional condition, copepods feed selectively to diversify their diets (Kleppel 1993). Many field studies have reported that copepods prefer dinoflagellates and ciliates to diatoms even when diatoms were generally more abundant (Gifford \& Dagg 1988, Fessenden \& Cowles 1994, Liu et al. 2005, 2010), suggesting that dinoflagellates and ciliates are good supplementary food for maintaining basic metabolism and growth of copepods. However, few studies have been carried out to reveal the nutritional advantage of dinoflagellates and ciliates for copepod reproduction (Kleppel et al. 1991, Broglio et al. 2003).

To define food quality, stoichiometric ratios (e.g. $\mathrm{C}: \mathrm{N}, \mathrm{C}: \mathrm{P}$ ) are frequently used (e.g. Anderson \& Pond 2000). For instance, egg production rate of marine zooplankton can be limited by short supply of nitro- 
gen, indicative of low concentrations of proteins in the food (Checkley 1980). According to the theory of stoichiometry, ciliates should be a good food item for copepods because ciliates generally have a low C:N ratio compared to most phytoplankton. For example, the development of copepods can be enhanced by a diet containing ciliates (Stoecker \& Capuzzo 1990). However, stoichiometric ratios are too simple as predictors and sometimes fail to represent the nutritional quality of food in terms of supporting copepod reproduction. It is believed that the reproductive success of copepods also depends on a balance of macronutrients, such as amino acids, sterols and essential fatty acids (Ederington et al. 1995, Kleppel et al. 1998, Guisande et al. 2000, Hassett 2004). The biochemical composition of ciliates can vary significantly depending on their food source, which makes the importance of ciliates for copepod reproduction uncertain (Broglio et al. 2003).

Polyunsaturated fatty acids (PUFAs) are indispensable nutrients that are involved in various key processes of marine copepods such as development and reproduction (Sargent \& Falk-Petersen 1988), primarily because PUFAs are the major components of phospholipids that play important roles in cell membrane structure and are important precursors of bioactive signalling molecules such as hormones that trigger some key processes of marine crustaceans (Harrison 1990). PUFAs are also an important source of energy in egg yolk lipovitellins that fuel successful egg hatching and early development (Kattner et al. 2007). However, copepods are unable or ineffective to synthesize PUFAs de novo so that it is important for copepods to obtain enough PUFAs from their food (Bell et al. 2007). As copepods rapidly utilize dietary fatty acids to maintain metabolism and growth, the limitations of essential PUFAs for reproduction are commonly found in marine ecosystems, especially in tropical and subtropical regions where few species develop storage lipids like polar and sub-polar species do (Kattner \& Hagen 2009). Similar to freshwater crustacean zooplankton (Brett \& Müller-Navarra 1997, Müller-Navarra et al. 2000), positive relationships between fecundity and the availability of PUFAs have been shown in various marine copepod species in both field and laboratory investigations (Lacoste et al. 2001, Arendt et al. 2005, Evjemo et al. 2008). In particular, copepods require critical amounts of long-chain $\omega 3$ PUFAs, including eicosapentaenoic acid (EPA) and docosahexaenoic acid (DHA), from the diet. Reproduction of copepods and cladocerans may be limited by either EPA or DHA, depending on zooplankton species, season and die- tary composition. For example, reproduction of freshwater Daphnia is primarily influenced by the availability of diatom-associated EPA (Persson \& Vrede 2006). The reproduction of some coastal copepods (Acartia, Paracalanus and Centropages) can also be limited by EPA during the seasons when diatoms are scarce (Vargas et al. 2006). Temora longicornis can be limited by the availability of dinoflagellates (marked by high DHA composition) during diatom blooms (Evjemo et al. 2008).

This study aimed to assess the relative importance of different fatty acids by comparing the relationships between copepod reproduction rate and specific fatty acids in diets. We conducted copepod feeding and egg production experiments by providing 5 different prey types with varying $\mathrm{C}: \mathrm{N}$ ratios and fatty acid profiles: a green alga Dunaliella sp. (absence of long-chain unsaturated fatty acids), the diatom Thalassiosira weissflogii (rich in EPA), the autotrophic dinoflagellate Prorocentrum dentatum (rich in DHA), a cryptophyte Rhodomonas sp. (moderate amount of EPA and DHA) and the bacteria-fed ciliate Strombidium sulcatum (no EPA or DHA, low C:N ratio). We hypothesized that different fatty acid compositions in diets can create a significant variability in egg production rate and egg hatching success of the subtropical calanoid copepod Acartia erythraea. To minimize any potential limitation effect of other bio-chemicals (such as sterols and essential amino acids) as a result of providing a mono-algal diet (Jónasdóttir et al. 2009), we fed the copepods a mixed diet combining treatment prey with the control alga Dunaliella sp.

\section{MATERIALS AND METHODS}

\section{Prey cultures}

The algal cultures including Dunaliella sp., Prorocentrum dentatum and Rhodomonas sp. were grown in $\mathrm{f} / 2$ medium under 14:10 h (light:dark cycle) illumination of approximately $100 \mu \mathrm{E} \mathrm{m}^{-2} \mathrm{~s}^{-1}$ in a walk-in culture room at $24^{\circ} \mathrm{C}$, while Thalassiosira weissflogii was grown in $\mathrm{f} / 2+\mathrm{Si}$ medium under the same irradiance and temperature. The ciliate Strombidium sulcatum was maintained in filtered seawater with rice grains as a nutrient source for bacteria. All cultures for copepod feeding experiments, elemental (carbon and nitrogen) and fatty acid analysis were kept at exponential phase. Algae for both elemental and fatty acid analysis were directly collected onto pre-combusted GF/C glass-fibre filters. Ciliates were first concentrated by $10 \mu \mathrm{m}$ polycarbonate membrane filters, and 
were then washed by autoclaved filtered seawater onto pre-combusted GF/C filters. Any visual aggregates from ciliate cultures were discarded from these filters. Filters containing algae and ciliates were then dried at $60^{\circ} \mathrm{C}$ for $24 \mathrm{~h}$ before being analysed by a Perkin-Elmer CHN elemental analyser, while filters for fatty acid analysis were stored at $-80^{\circ} \mathrm{C}$ for further analysis. Cell numbers of Dunaliella sp., Rhodomonas sp., P. dentatum and T. weissflogii were determined by a Z2 particle counter (Beckman-Coulter). The cell numbers of ciliates were determined by microscopic counting. Equivalent spherical diameters of the 5 species determined by Coulter-Counter (Beckman-Coulter) are shown in Table 1.

\section{Feeding and egg production experiments}

We prepared 5 different food combinations. The first was a mono-algal diet of Dunaliella sp., which served as a control diet due to the absence of longchain PUFAs that should limit copepod egg production (e.g. Støttrup \& Jensen 1990, Zhukova \& Aizdaicher 1995, Lacoste et al. 2001, Arendt et al. 2005). The other 4 were mixed diets combining Dunaliella sp. with either Rhodomonas sp., Thalassiosira weissflogii, Prorocentrum dentatum or Strombidium sulcatum to achieve a gradient of $\mathrm{C}: \mathrm{N}$ ratio and different compositions of fatty acids among treatments. Initial concentrations of 1367 to $3087 \mu \mathrm{C} \mathrm{Cl}^{-1}$ (Table 1) were set up at similar carbon levels among treatments based on prey sizes in $600 \mathrm{ml}$ polycarbonate bottles.

Experimental copepods were collected by net tows from Port Shelter, Hong Kong, in May 2009. To ensure the same initial gut condition of copepods before experiments, copepods were first transferred to a $201 \mathrm{PC}$

Table 1. Equivalent spherical diameter (ESD, $\mu \mathrm{m})$, initial concentrations (cells $\mathrm{ml}^{-1}$ ) of each prey and total carbon concentrations $\left(\mu \mathrm{g}^{-1}\right.$ ) of each treatment in copepod feeding experiments. Treatments were mixed diets combining Dunaliella sp. with either Rhodomonas sp. (RHO), Thalassiosira weissflogii (THA), Prorocentrum dentatum (PRO) or Strombidium sulcatum (STR)

\begin{tabular}{|lccccccc|}
\hline \multirow{2}{*}{ Prey } & \multirow{2}{*}{ ESD Control } & \multicolumn{5}{c|}{ Treatments } & \\
\cline { 4 - 7 } & & & RHO & THA & PRO & STR \\
\hline Dunaliella sp. & 6.7 & 10000 & 5000 & 5000 & 5000 & 5000 \\
Rhodomonas sp. & 7.1 & & 5000 & & & \\
$\begin{array}{l}\text { T. weissflogii } \\
\text { P. dentatum }\end{array}$ & 12.2 & & & 2000 & & \\
S. sulcatum & 24.1 & & & & 2000 & \\
Total carbon & & 1473 & 1367 & 2047 & 3087 & 2761 \\
\hline
\end{tabular}

carboy containing Dunaliella sp. at a concentration of approximately 5000 cells ml $^{-1}\left(740 \mu \mathrm{g} \mathrm{Cl}^{-1}\right)$ at $24^{\circ} \mathrm{C}$ for $1 \mathrm{~d}$. Active, healthy adult female Acartia erythraea individuals were then sorted from the copepod assemblage under a dissecting microscope and transferred in groups of 12 to triplicate experimental bottles. These were incubated in the dark for $24 \mathrm{~h}$ at $24^{\circ} \mathrm{C}$. Duplicate control bottles containing the 5 foods without copepods were incubated under the same conditions. After incubation, the final concentration of each prey was determined and feeding rates calculated based on the equations of Frost (1972). The calculation of ingestion rates of Dunaliella sp. in the STR treatment was modified owing to a trophic cascading effect (the difference of microzooplankton grazing rate with and without copepod presence) according to Nejstgaard et al. (2001). As the sizes of Dunaliella sp. and Rhodomonas sp. overlapped, their final concentrations in the RHO treatment were determined by a FACSCalibur flow cytometer. Ingestion rates of total carbon, total nitrogen, total fatty acids and specific fatty acids were estimated by multiplying individual specific ingestion rate with elemental or biochemical contents per prey cell.

Half of copepods fed with different diet combinations were recovered from the bottles after $24 \mathrm{~h}$ incubation to carry out egg production experiments. The egg production rates of Acartia erythraea were estimated by incubating recovered females in 6-well plates $\left(15 \mathrm{ml}\right.$ in each well) at $24^{\circ} \mathrm{C}$ for $24 \mathrm{~h}$. Each female was separately placed in a well containing the same food as in previous feeding experiments (18 replicates per treatment). At the end of the experiments, the total numbers of eggs including empty egg shells in the plates were counted under the microscope. Only eggs in the plates where the copepods were still alive were counted. The remaining eggs from different treatments (10 replicates per treatment) were incubated for a further $24 \mathrm{~h}$ to determine hatching success. More than half of the eggs that could finally be hatched successfully were normally hatched within the first $24 \mathrm{~h}$ egg production experiment, so the eggs were incubated for $48 \mathrm{~h}$ in total from the beginning of the egg production experiments.

\section{Fatty acid analysis of food}

The fatty acid compositions of duplicate prey samples were analysed by gas chromatography. Fatty acid extraction and analysis followed the procedures described by Folch et al. (1957) and Kattner \& Fricke (1986). Filters containing experimental prey were 
placed in pre-combusted test tubes, sonicated in an ice bath $(5 \mathrm{~min})$, centrifuged $(967.68 \times g$ based on radius of $15 \mathrm{~cm}, 5 \mathrm{~min}$ ), and extracted in a mixture of $\mathrm{CH}_{2} \mathrm{Cl}_{2}$ :methanol:water (8:4:3,v:v:v). The organic phase containing fatty acids was collected from the tubes. The extraction procedures were run for an additional 3 times to wash out the remains of GF/F filters and to collect the organic phase. Fatty acids in the organic phase were then transmethylated to fatty acid methyl ester derivatives (FAMEs) in $0.5 \mathrm{ml} \mathrm{n}$ hexane and $3 \mathrm{ml}$ methanol containing $3 \%$ concentrated sulphuric acid at $80^{\circ} \mathrm{C}$ for $4 \mathrm{~h}$. After cooling, the FAMEs were extracted by adding $4 \mathrm{ml}$ distilled water and $3 \mathrm{ml} \mathrm{n}$-hexane and were centrifuged at $2400 \mathrm{rpm}$ for $5 \mathrm{~min}$. After washing 3 times, extracts containing FAMEs were dried by nitrogen gas and stored at $-20^{\circ} \mathrm{C}$ until gas chromatography analysis, for which the FAME samples were injected into a gas chromatograph (Agilent 7890A) equipped with a capillary column (DB-FFAP, $30 \mathrm{~m} \times 0.32 \mathrm{~mm} \times$ $0.25 \mu \mathrm{m})$ using helium as the carrier gas. The injection and detection temperatures were 220 and $280^{\circ} \mathrm{C}$, respectively. The initial column temperature was $150^{\circ} \mathrm{C}$ (held isothermal for $3 \mathrm{~min}$ ), and subsequently the column temperature was increased by $3^{\circ} \mathrm{C} \mathrm{min}{ }^{-1}$ until $220^{\circ} \mathrm{C}$ and kept isothermal for $33 \mathrm{~min}$. FAMEs were then detected by flame ionization and identified and quantified by comparing retention time and area of peaks with those derived from standards (Sigma) of known composition. Fatty acids in mixed standards included: 10:0, 11:0, 12:0, 13:0,14:0,14:1, $15: 0,15: 1,16: 0,16: 1 \omega 7,16: 3 \omega 4,17: 0,17: 1,18: 0$, $18: 1 \omega 9,18: 2 \omega 6,18: 3 \omega 3,18: 4 \omega 3,19: 0,20: 0,20: 2 \omega 6$, $20: 3 \omega 6,20: 4 \omega 6,23: 0,20: 5 \omega 3,22: 0,22: 1 \omega 9,22: 2$, 22:6 $\omega 3,24: 0$ and $24: 1$. The fatty acid 19:0 was added prior to sample analysis as an internal standard.

\section{Data analysis}

Mean ingestion and egg production rates among treatments and control were compared by 1-way analysis of variance (ANOVA). To find relationships between food quality and egg production rate, we performed generalized additive models (GAMs) to separate the effects of ingested fatty acids and nitrogen from ingested total carbon. The dependent variable, the egg production rate, was modelled as the additive sum of unspecific non-parametric functions of covariates, including ingested carbon, nitrogen, saturated fatty acids (SAFAs), monounsaturated fatty acids (MUFAs) and PUFAs. A backward stepwise method was used to find the best model based on the values of generalized cross validation (GCV), Akaike information criterion (AIC) and deviance explained by models. Predictors that had the smallest $F$ values were manually removed from the full models to the reduced models. Other GAM tests were also performed to reveal the importance of ingested fatty acid groups (SAFAs, MUFAs and PUFAs) and essential fatty acids in hatching success. All GAM tests were performed using the mgcv package in R software version 2.14.0 (R Development Core Team). We used Gaussian family (normal distribution) and cubic regression spline to smooth the predictors, with a degrees of freedom of 3 . To further compare the coefficients of specific PUFAs on egg production rate and hatching success, we performed partial correlation analysis using SPSS 14.0. To improve normality for statistically tests, the data of egg production rate were log transformed, while the data of egg hatching percentage were arcsine transformed.

\section{RESULTS}

\section{Elemental composition and fatty acid profile}

Contents of carbon, nitrogen and fatty acids, and $\mathrm{C}: \mathrm{N}$ ratios of the 5 species are shown in Table 2 . The 2 small-sized species Dunaliella sp. and Rhodomonas sp. had similar carbon contents. Prorocentrum dentatum had a significantly higher carbon content than Thalassiosira weissflogii, although they had similar equivalent spherical diameters. The $\mathrm{C}: \mathrm{N}$ ratios ranged from 4.6 to 6.8 , with high ratios in Dunaliella

Table 2. Mean $\left( \pm \mathrm{SD}\right.$ ) cell-specific carbon, nitrogen and fatty acid contents (all given in ng cell ${ }^{-1}$ ), and C:N ratios of 5 different species

\begin{tabular}{|lcccc|}
\hline Prey & Carbon & Nitrogen & Fatty acids & C:N ratio \\
\hline Dunaliella sp. & $0.147 \pm 0.006$ & $0.022 \pm 0.001$ & $0.005 \pm 0.002$ & 6.8 \\
Rhodomonas sp. & $0.126 \pm 0.002$ & $0.027 \pm 0.001$ & $0.005 \pm 0.001$ & 4.6 \\
Thalassiosira weissflogii & $0.262 \pm 0.005$ & $0.046 \pm 0.001$ & $0.016 \pm 0.004$ & 5.7 \\
Prorocentrum dentatum & $1.176 \pm 0.090$ & $0.176 \pm 0.013$ & $0.039 \pm 0.004$ & 6.7 \\
Strombidium sulcatum & $20.247 \pm 5.758$ & $4.403 \pm 1.252$ & $1.607 \pm 0.737$ & 4.6 \\
\hline
\end{tabular}


sp. and $P$. dentatum and low ratios in Rhodomonas sp. and Strombidium sulcatum.

Carbon-specific fatty acids, ratios of essential fatty acids and fatty acid compositions are shown in Tables $3 \& 4$. Total fatty acids ranged from 32.8 to $79.4 \mu \mathrm{g} \mathrm{mg} \mathrm{C}^{-1}$, and were about 2 times higher in the ciliate Strombidium sulcatum and the diatom Thalassiosira weissflogii than in the other 3 species. The major group of fatty acids in $S$. sulcatum were SAFAs, especially those with 16 and 18 carbons in the fatty acid chain. The highest concentration of MUFAs was also found in the $S$. sulcatum. Overall, $S$. sulcatum contained relatively low amounts of PUFAs

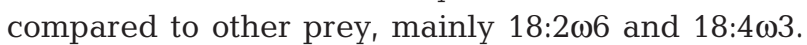
No highly unsaturated fatty acids (HUFAs) were detected in this species. The highest PUFA concen-

Table 3. Carbon-specific fatty acid contents $\left(\mu \mathrm{g} \mathrm{mg} \mathrm{C}^{-1}\right)$, summary of total and specific groups of fatty acids and important ratios of fatty acids of 5 different species. The values are averaged from duplicate samples. $\sum$ : sum, SAFAs: saturated fatty acids, MUFAs: monounsaturated fatty acids (only 1 double bond), PUFAs: polyunsaturated fatty acids ( 2 or more double bonds), LIN: linoleic acid, ALA: alpha-linolenic acid, SDA: stearidonic acid, ARA: arachidonic acid, EPA: eicosapentaenoic acid, DHA: docosahexaenoic acid

\begin{tabular}{|c|c|c|c|c|c|}
\hline Fatty acids & $\begin{array}{l}\text { Dunaliella } \\
\text { sp. }\end{array}$ & $\begin{array}{l}\text { Rhodomonas } \\
\text { sp. }\end{array}$ & $\begin{array}{c}\text { Thalassiosira } \\
\text { weissflogii }\end{array}$ & $\begin{array}{l}\text { Prorocentrum } \\
\text { dentatum }\end{array}$ & $\begin{array}{l}\text { Strombidium } \\
\text { sulcatum }\end{array}$ \\
\hline $14: 0$ & 0.2 & 2.8 & 13.5 & 0.6 & 1.9 \\
\hline 16:0 & 9.9 & 8.4 & 11.6 & 11.1 & 35.4 \\
\hline $16: 1 \omega 7$ & 0.3 & 0.4 & 8.3 & 0.1 & 6.3 \\
\hline $16: 3 \omega 4$ & 0.0 & 0.0 & 1.3 & 0.0 & 0.6 \\
\hline $17: 0$ & 0.5 & 0.0 & 0.0 & 0.0 & 0.0 \\
\hline $18: 0$ & 2.6 & 2.8 & 2.4 & 2.5 & 18.7 \\
\hline $18: 1 \omega 9$ & 1.1 & 1.8 & 0.7 & 0.8 & 4.3 \\
\hline 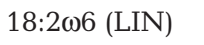 & 2.6 & 3.1 & 2.0 & 2.2 & 8.6 \\
\hline 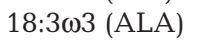 & 13.9 & 6.9 & 0.8 & 0.7 & 0.0 \\
\hline $18: 4 \omega 3$ (SDA) & 1.8 & 0.9 & 0.0 & 0.0 & 3.6 \\
\hline $18: 5 \omega 3$ & 0.0 & 0.0 & 0.0 & 8.0 & 0.0 \\
\hline $20: 0$ & 0.0 & 0.0 & 0.0 & 0.1 & 0.0 \\
\hline $20: 4 \omega 6$ (ARA) & 0.0 & 0.3 & 0.0 & 0.0 & 0.0 \\
\hline 20:5 03 (EPA) & 0.0 & 5.8 & 18.6 & 0.5 & 0.0 \\
\hline 22:6w3 (DHA) & 0.0 & 2.9 & 3.2 & 6.2 & 0.0 \\
\hline$\sum$ fatty acids & 32.8 & 36.2 & 62.2 & 32.8 & 79.4 \\
\hline$\sum$ SAFAs & 13.2 & 14.0 & 27.4 & 14.4 & 56.0 \\
\hline$\sum$ MUFAs & 1.4 & 2.2 & 9.0 & 0.9 & 10.6 \\
\hline$\sum$ PUFAs & 18.3 & 20.0 & 24.6 & 17.6 & 12.2 \\
\hline$\sum \omega 3$ & 15.7 & 16.6 & 22.6 & 15.4 & 3.6 \\
\hline$\sum \omega 6$ & 2.6 & 3.4 & 2.0 & 2.2 & 8.6 \\
\hline
\end{tabular}

Table 4. Fatty acid composition (expressed as percentage of total fatty acids) of 5 different prey. See Table 3 for abbreviations

\begin{tabular}{|c|c|c|c|c|c|}
\hline Fatty acids & $\begin{array}{l}\text { Dunaliella } \\
\text { sp. }\end{array}$ & $\begin{array}{l}\text { Rhodomonas } \\
\text { sp. }\end{array}$ & $\begin{array}{c}\text { Thalassiosira } \\
\text { weissflogii }\end{array}$ & $\begin{array}{l}\text { Prorocentrum } \\
\text { dentatum }\end{array}$ & $\begin{array}{l}\text { Strombidium } \\
\text { sulcatum }\end{array}$ \\
\hline $14: 0$ & 0.7 & 7.1 & 21.6 & 1.7 & 2.4 \\
\hline 16:0 & 29.4 & 23.1 & 18.6 & 33.9 & 44.3 \\
\hline $16: 1 \omega 7$ & 0.7 & 1.1 & 13.4 & 0.2 & 7.9 \\
\hline $16: 3 \omega 4$ & 0.0 & 0.0 & 2.0 & 0.0 & 0.8 \\
\hline $17: 0$ & 1.6 & 0.0 & 0.0 & 0.0 & 0.0 \\
\hline 18:0 & 7.6 & 8.4 & 3.8 & 7.7 & 23.8 \\
\hline $18: 1 \omega 9$ & 3.5 & 5.8 & 1.1 & 2.5 & 5.3 \\
\hline 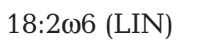 & 8.3 & 8.5 & 3.1 & 6.6 & 11.0 \\
\hline 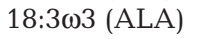 & 42.7 & 18.6 & 1.2 & 2.1 & 0.0 \\
\hline 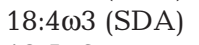 & 5.6 & 2.6 & 0.0 & 0.0 & 4.6 \\
\hline $18: 5 \omega 3$ & 0.0 & 0.0 & 0.0 & 24.3 & 0.0 \\
\hline $20: 0$ & 0.0 & 0.0 & 0.0 & 0.4 & 0.0 \\
\hline 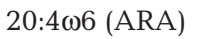 & 0.0 & 0.8 & 0.0 & 0.0 & 0.0 \\
\hline $20: 5 \omega 3$ (EPA) & 0.0 & 16.1 & 30.0 & 1.5 & 0.0 \\
\hline 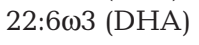 & 0.0 & 7.8 & 5.1 & 19.0 & 0.0 \\
\hline
\end{tabular}


trations were found in the diatom $T$. weissflogii, with the majority as $\omega 3$ unsaturated fatty acids, of which the majority were HUFAs, especially the fatty acid 20:5 03 (EPA). Less than half of the PUFAs in Rhodomonas sp. were composed of HUFAs. Among HUFAs in Rhodomonas sp., the percentage of EPA was 2

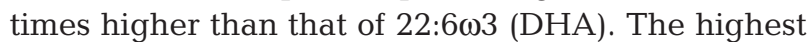
DHA concentration was found in the dinoflagellate Prorocentrum dentatum. However, the dinoflagellate contained low absolute amount of carbon-specific PUFAs, HUFAs or $\omega 3$ unsaturated fatty acids due to low amounts of 18:3 $\omega 3$ (ALA) and EPA. HUFAs were not found in the green alga Dunaliella sp., but total PUFA or $\omega 3$ unsaturated fatty acid concentrations were not very low in Dunaliella sp. compared to those in the dinoflagellate and ciliate. The majority of PUFAs or $\omega 3$ unsaturated fatty acids were composed of ALA, contributing more than $40 \%$ to total fatty acids.

Since different species had specific profiles of $C_{1} N$ elements and fatty acids, different treatments contained different concentrations of carbon, nitrogen, total and specific fatty acids. For example, initial total fatty acids among treatments ranged from 47 to

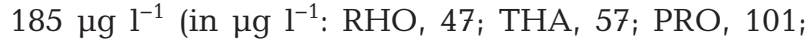
$\mathrm{STR}$, 185). HUFAs ranged from 0 to $16 \mathrm{ng} \mathrm{ml}^{-1}$, with the highest concentration in the PRO treatment.

\section{Copepod clearance rate and ingestion rate}

Copepod clearance rates on different prey are shown in Fig. 1. The clearance rates on Prorocentrum dentatum and Strombidium sulcatum at respective treatments were significantly higher than those on Dunaliella sp. (ANOVA, p < 0.05), indicating an apparent feeding preference on these 2 large-sized prey. Clearance rates on Dunaliella sp. in the RHO and THA treatments were significantly higher than that in controls (ANOVA, $\mathrm{p}<0.05$ ), suggesting that the feeding activity was increased in the presence of Rhodomonas sp. and Thalassiosira weissflogii compared to the controls.

Ingestion rates for carbon, nitrogen and total fatty acids showed an increase from controls to treatments (Fig. 2). Overall, the trends for nitrogen and fatty acids were similar to ingestion of total carbon (Pearson correlations, $\mathrm{p}<0.001$ ). Highest ingestion rates based on carbon and nitrogen were observed in the PRO treatment, while the highest ingestion rate based on total fatty acids was observed in the STR treatment. Due to apparent feeding selectivity (cf. Fig. 1), ingestion rates in the PRO and STR treatments were mostly determined by Prorocentrum dentatum and Strombidium sulcatum, respectively. However, Dunaliella sp. contributed almost equivalently to Rhodomonas sp. and Thalassiosira weissflogii in the RHO and THA treatments, respectively. When provided with a mono-algal diet, copepods ingested significantly lower amounts of all 3 components (carbon, nitrogen and total fatty acids).

Ingestion rates on specific fatty acids also varied among treatments (Fig. 3), reflecting the availability of different fatty acids in each treatment. The STR treatment showed the highest ingestion rates among treatments of saturated, monounsaturated and $\omega 3$ unsaturated fatty acids, but the lowest ingestion rates of $\omega 3$ unsaturated fatty acids (Fig. 3A,B). Due to the lack of HUFAs in both Dunaliella sp. and Strombidium sulcatum, there was no ingestion of HUFAs in the STR treatment and the control (Fig. 3C). The highest HUFA ingestion rates were primarily determined by DHA and hence the highest ingestion rates on PUFAs and $\omega 3$ unsaturated fatty acids were observed in the PRO treatment containing Prorocentrum dentatum. Ingestion of HUFAs and total $\omega 3$ unsaturated fatty acids (primarily composed of EPA) were also high in the THA treatment containing Thalassiosira weissflogii, but this treatment only showed a low ingestion rate on DHA. The RHO treatment containing Rhodomonas sp. resulted in low ingestion rates on both EPA and DHA, but ingestion rates on HUFAs and $\omega 3$ unsaturated fatty acids were significantly higher than in the control and STR treatment.

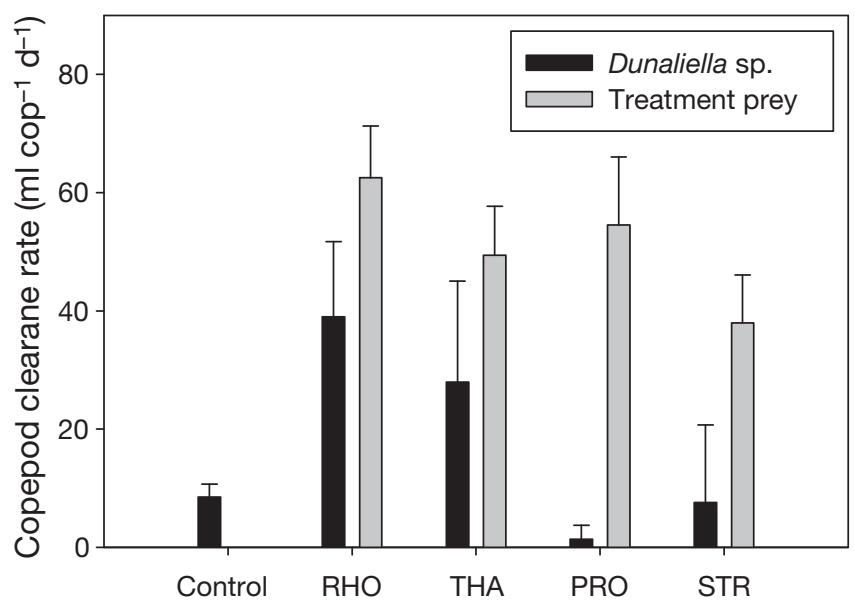

Fig. 1. Copepod (cop) clearance rates on different prey species among different treatments and control. Error bar indicates SD among triplicates. Treatments combined Dunaliella sp. with either Rhodomonas sp. (RHO), Thalassiosira weissflogii (THA), Prorocentrum dentatum (PRO) or Strombidium sulcatum (STR) 


\section{Egg production rates and relationships with specific fatty acids}

Egg production rates of the copepods fed the different diets (Fig. 4) were significantly different among treatments (ANOVA, $\mathrm{p}<0.001$ ). The highest egg pro-
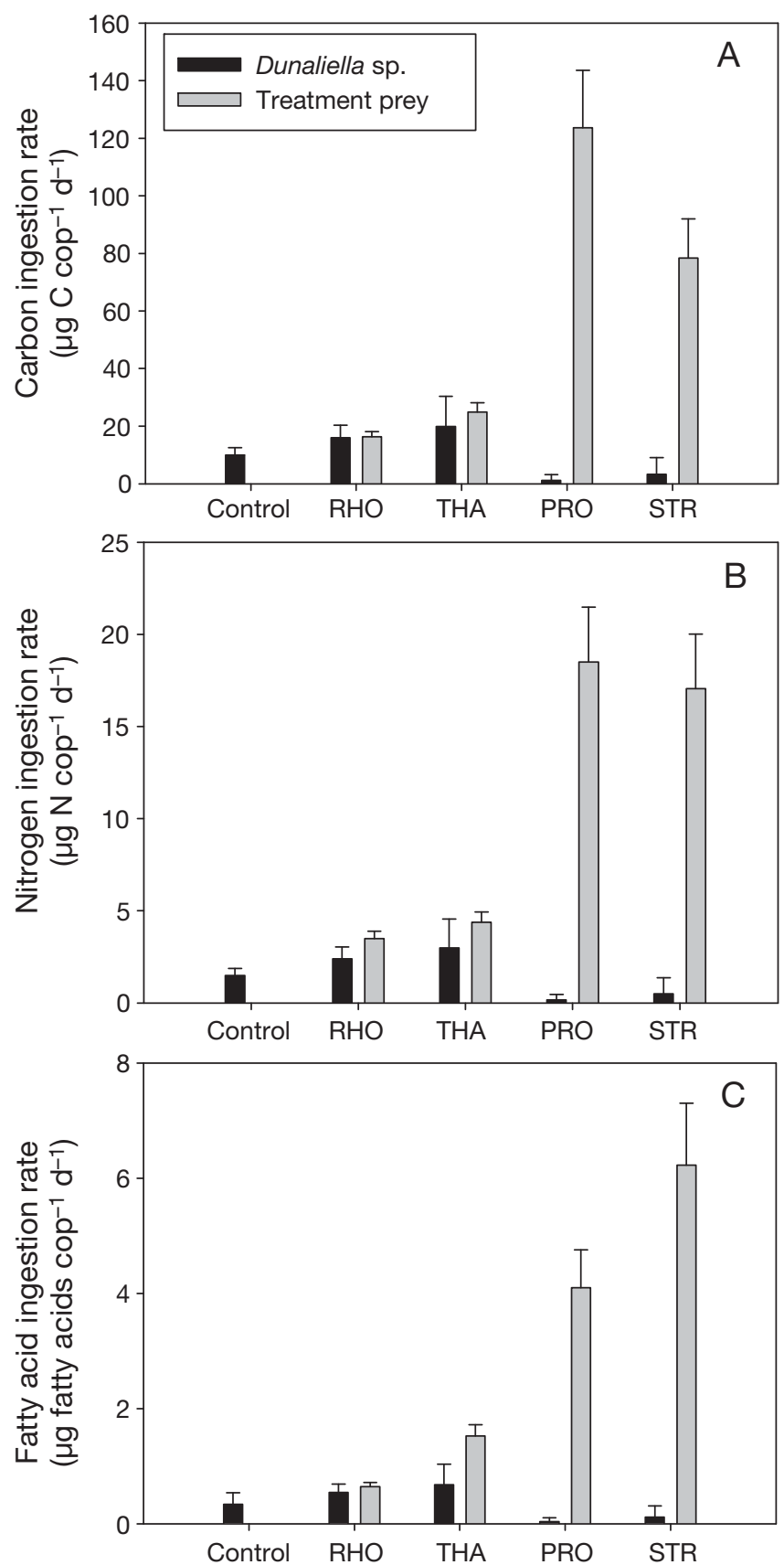

Fig. 2. Copepod (cop) ingestion rates for (A) carbon, (B) nitrogen and $(\mathrm{C})$ total fatty acids among different treatments and control. Error bar indicates SD among triplicates. Treatments combined Dunaliella sp. with either Rhodomonas sp. (RHO), Thalassiosira weissflogii (THA), Prorocentrum dentatum (PRO) or Strombidium sulcatum (STR) duction rates were observed in the PRO treatment, with an average of 38 eggs female ${ }^{-1} \mathrm{~d}^{-1}$, indicating the high food quality of the mixture of Prorocentrum dentatum and Dunaliella sp. Rates in the RHO and THA treatments were significantly higher than in the
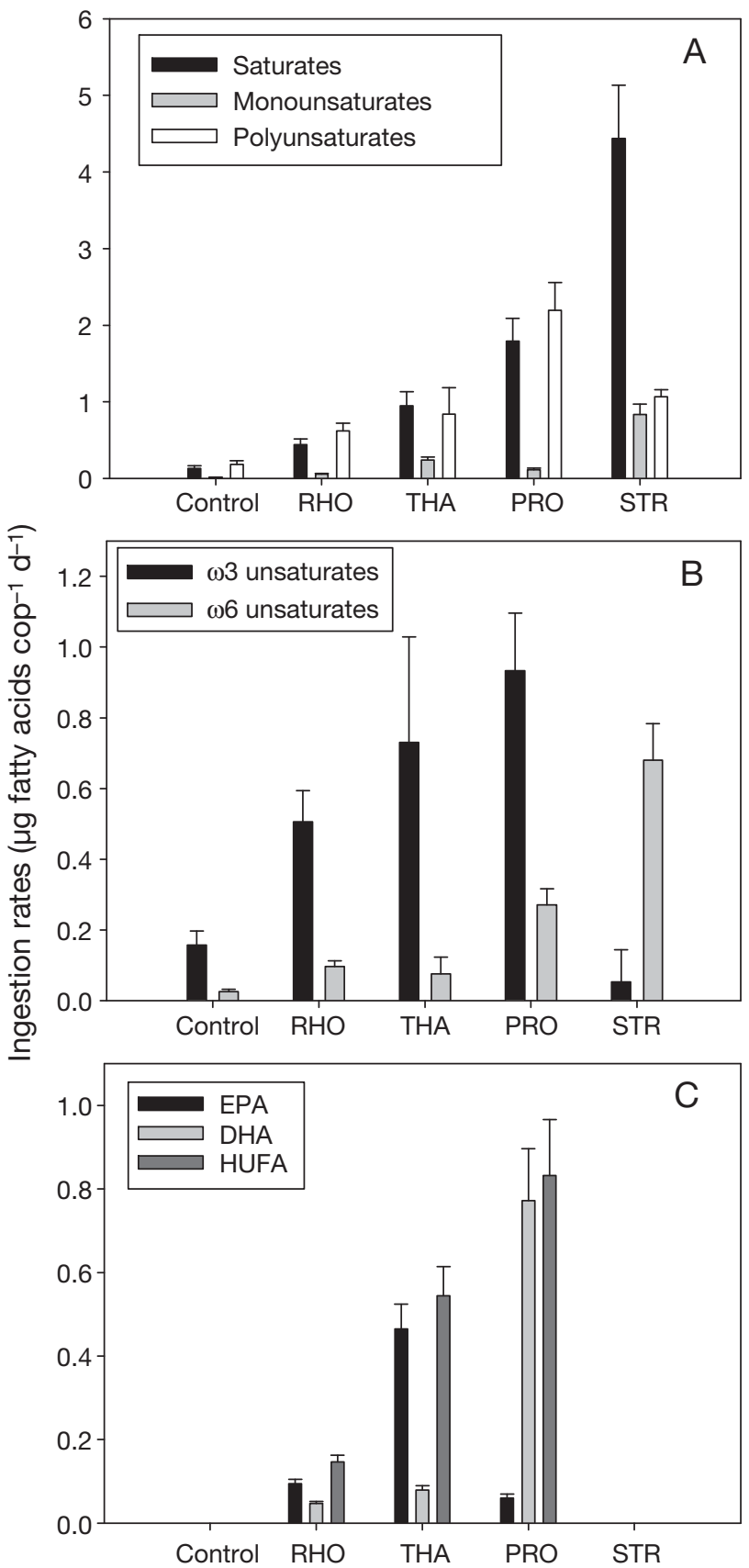

Fig. 3. Copepod (cop) ingestion rates on specific fatty acid groups: (A) saturates, monounsaturates and polyunsaturates; (B) $\omega 3$ and $\omega 6$ unsaturates; (C) EPA, DHA and total longchain unsaturates. Error bar indicates SD among triplicates. Treatments combined Dunaliella sp. with either Rhodomonas sp. (RHO), Thalassiosira weissflogii (THA), Prorocentrum dentatum (PRO) or Strombidium sulcatum (STR) 


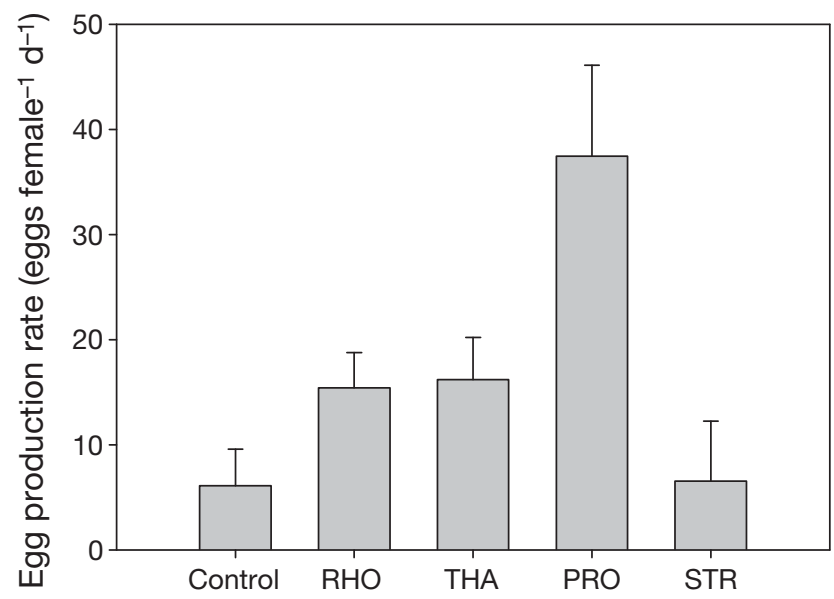

Fig. 4. Acartia erythraea. Egg production rates of females fed on different diets. Error bar indicates SD among replicates. Treatments combined Dunaliella sp. with either Rhodomonas sp. (RHO), Thalassiosira weissflogii (THA), Prorocentrum dentatum (PRO) or Strombidium sulcatum (STR)

control, but were both less than half that of the PRO treatment. The lowest egg production rate was found in the STR treatment, about 6 eggs female ${ }^{-1} \mathrm{~d}^{-1}$, which was not significantly different from the control, suggesting nutritional inadequacy of the ciliate.
Results of the GAM test indicated that egg production rates were influenced by both food quantity and food quality (Table 5). The full model including ingested total carbon, nitrogen and 3 groups of fatty acids explained $71.3 \%$ of the variation in egg production rates in total. Partial effects of each parameter on egg production rate in the full model are shown in Fig. 5. Overall, ingested nitrogen, PUFAs and MUFAs had positive effects on egg production rates, while ingested total carbon and SAFAs had negative effects in the full model. The deviance that was explained by predictors remained the same when ingested SAFAs and MUFAs were removed from the models. The best fit of model was model 2 (parameters including ingested total carbon, nitrogen and PUFAs) based on its lowest values of GCV and $\mathrm{AIC}$, in which all parameters were significant and PUFAs had the highest $F$ value (ratio of explained variance/unexplained variance). The removal of ingested nitrogen from model 2 to model 3 caused only a slight decrease of deviance explained $(0.9 \%)$, while the removal of ingested PUFAs caused a substantial decrease of deviance explained $(36.4 \%)$. This result indicated that the importance of PUFAs was greater than that of nitrogen in the

Table 5. Effects of ingested nutrition on variations of copepod egg production rates (EPR) revealed by generalized additive models (GAMs). The relative goodness of fit of a model is indicated by the generalized cross validation (GCV) and Akaike information criterion (AIC). Spline (s) in all models is the smooth function, while b is the constant. The deviance of EPR explained by predictors involved is also shown. The best fitting model with the lowest GCV and AIC is shown in bold. Relative strengths of individual predictors in a model are compared by $F$ values and significance (p). The predictor with the smallest explained $F$ value among all predictors in a previous model is reduced in the next model. ns: not significant. SAFA: saturated fatty acid, MUFA: monounsaturated fatty acid, PUFA: polyunsaturated fatty acid

\begin{tabular}{|c|c|c|c|c|c|c|c|}
\hline Model & & GCV score & AIC & Deviance explained (\%) & Predictors & $F$ & $\mathrm{p}$ \\
\hline \multicolumn{8}{|l|}{ Full model } \\
\hline \multirow[t]{5}{*}{ Log EPR = } & $\mathrm{s}($ Carbon $)+\mathrm{s}(\mathrm{PUFA})$ & 0.062 & 4.4 & 71.3 & s(Carbon) & 5.9 & 0.032 \\
\hline & $+\mathrm{s}($ Nitrogen $)+\mathrm{s}(\mathrm{SAFA})$ & & & & $\mathrm{s}(\mathrm{PUFA})$ & 4.0 & ns \\
\hline & $+\mathrm{s}(\mathrm{MUFA})+\mathrm{b}$ & & & & s(Nitrogen) & 5.7 & 0.021 \\
\hline & & & & & s(SAFA) & 10.8 & 0.003 \\
\hline & & & & & $\mathrm{s}(\mathrm{MUFA})$ & 3.4 & ns \\
\hline \multicolumn{8}{|l|}{ Model 1} \\
\hline \multirow[t]{4}{*}{ Log EPR = } & $\mathrm{s}($ Carbon $)+\mathrm{s}(\mathrm{PUFA})$ & 0.062 & 4.4 & 71.3 & s(Carbon) & 5.9 & 0.018 \\
\hline & $+\mathrm{s}($ Nitrogen $)+\mathrm{s}(\mathrm{SAFA})+\mathrm{b}$ & & & & s(PUFA) & 4.7 & 0.035 \\
\hline & & & & & s(Nitrogen) & 3.0 & ns \\
\hline & & & & & $\mathrm{s}(\mathrm{SAFA})$ & 0.02 & ns \\
\hline \multicolumn{8}{|l|}{ Model 2} \\
\hline \multirow[t]{3}{*}{ Log EPR = } & $\mathrm{s}($ Carbon $)+\mathrm{s}(\mathrm{PUFA})$ & 0.059 & 2.4 & 71.3 & s(Carbon) & 18.4 & $<0.001$ \\
\hline & $+\mathrm{s}($ Nitrogen $)+\mathrm{b}$ & & & & s(PUFA) & 31.1 & $<0.001$ \\
\hline & & & & & s(Nitrogen) & 9.3 & 0.004 \\
\hline \multicolumn{8}{|l|}{ Model 3} \\
\hline \multirow[t]{2}{*}{ Log EPR = } & $\mathrm{s}($ Carbon $)+\mathrm{s}(\mathrm{PUFA})+\mathrm{b}$ & 0.061 & 3.8 & 70.4 & s(Carbon) & 40.2 & $<0.001$ \\
\hline & & & & & $\mathrm{s}$ (PUFA) & 32.6 & $<0.001$ \\
\hline \multicolumn{8}{|l|}{ Model 4} \\
\hline $\log \mathrm{EPR}=$ & $\mathrm{s}($ Carbon $)+\mathrm{b}$ & 0.127 & 45.1 & 34 & s(Carbon) & 27.8 & $<0.001$ \\
\hline
\end{tabular}



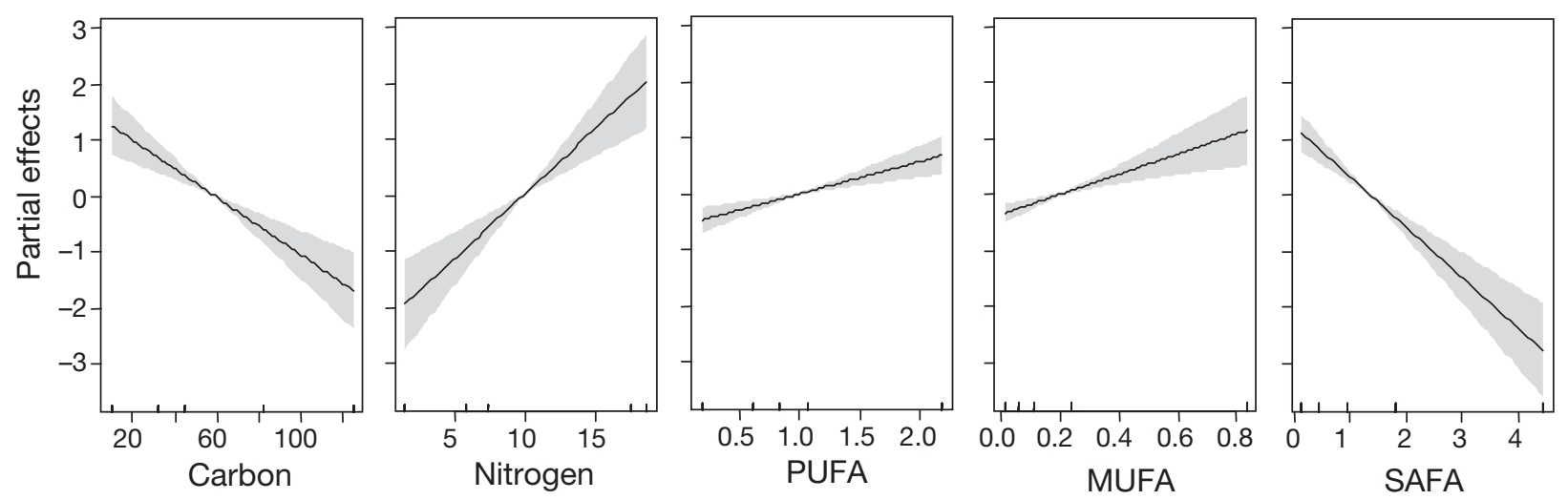

Fig. 5. Partial effects of predictors on variations of egg production rates in the full model (see Table 5). The smoothes of partial effects of predictors are shown as the black line, with the $95 \%$ CI (shading). SAFA: saturated fatty acid, MUFA: monounsaturated fatty acid, PUFA: polyunsaturated fatty acid

experiments. If no food quality factors were considered, ingested total carbon (food quantity) alone could only explain $34 \%$ of the variation in egg production rates (model 4), and the correlations were significant and positive (Pearson correlation, $\mathrm{r}=$ 0.583, $\mathrm{p}<0.001$ ).

To further illustrate the effect of individual fatty acids among PUFAs on egg production rates, partial correlation coefficients of specific PUFAs were compared (Table 6). Significance levels indicated that $\omega 3$ unsaturated fatty acids (DHA, EPA, 18:5 $\omega 3$ and ALA) were highly positively correlated with egg production rates, while stearidonic acid (SDA) and linoleic acid (LIN) were negatively correlated (Table 6). Overall, the 2 long-chain fatty acids (DHA and EPA) had higher coefficients than the 2 short-chain fatty

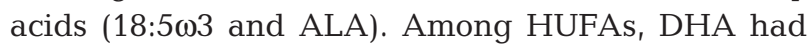
higher coefficients than EPA. The $\omega 3$ unsaturated fatty acid LIN was negatively correlated with egg production rates.

Table 6 . Coefficients of partial correlation between ingested specific polyunsaturated fatty acids (PUFAs) and egg production rates and egg hatching success. Ingestion rate of total PUFAs was controlled as the first order factor to avoid co-linearity. ${ }^{*} \mathrm{p}<0.05,{ }^{* *} \mathrm{p}<0.01$, ns: not significant

\begin{tabular}{|lcc|}
\hline \multirow{2}{*}{ Fatty acids } & \multicolumn{2}{c|}{ Coefficients } \\
\cline { 2 - 3 } & $\begin{array}{c}\text { Egg production rate } \\
\left(\text { eggs female } \mathrm{d}^{-1}\right)\end{array}$ & \\
\hline $22: 6 \omega 3$ (DHA) & $0.701^{* *}$ & $0.430^{* *}$ \\
$20: 5 \omega 3$ (EPA) & $0.513^{* *}$ & $0.328^{*}$ \\
$18: 3 \omega 3$ (ALA) & $0.510^{* *}$ & $0.461^{* *}$ \\
$18: 5 \omega 3$ & $0.360^{* *}$ & $0.320^{*}$ \\
$20: 4 \omega 6$ (ARA) & $\mathrm{ns}$ & $\mathrm{ns}$ \\
$18: 4 \omega 3$ (SDA) & $-0.534^{* *}$ & $-0.569^{* *}$ \\
$18: 2 \omega 6$ (LIN) & $-0.686^{* *}$ & $-0.585^{* *}$ \\
\hline
\end{tabular}

\section{Egg hatching percentage and relationships with diet composition}

Fig. 6 shows the frequency distribution and means of egg hatching percentage of copepods fed on different diets. Overall, hatching percentage was low in our experiment. Nevertheless, the mean hatching percentages were higher in the THA and PRO treatments in which approximately half of the eggs were hatched within $48 \mathrm{~h}$, as compared to the RHO treatment and dietary control $(42 \%$ and $33.5 \%$, respectively). A significantly lower percentage was observed for the eggs produced in the STR treatment (ANOVA, p < 0.01), indicative of the low nutritional quality of Strombidium culcatum.

Egg hatching percentages were significantly correlated with egg production rates (Pearson correlation, $\mathrm{r}=0.536, \mathrm{p}<0.01)$ but not significantly correlated with ingested total carbon (Pearson correlation, $\mathrm{p}>$ 0.05), suggesting that effects of food quality on egg production rates also affected the egg hatching success, whereas food quantity was not influential. Similar to the variation in egg production rates, ingested SAFAs $(F=6.4, \mathrm{p}=0.015)$ had a negative partial effect on egg hatching, while ingested PUFAs $(F=$ 9.7, $\mathrm{p}=0.003$ ) had positive partial effects on egg hatching based on the GAM test. Ingested MUFAs were not significantly correlated $(F=2.7, \mathrm{p}>0.05)$. The ingestion of these 3 fatty acid groups explained $42.3 \%$ of variation in egg hatching in total.

Similar to egg production rates, egg hatching percentages were significantly positively correlated with the $4 \omega 3$-PUFAs and negatively correlated with SDA and LIN (Table 6). However, the coefficients of the 3 major $\omega 3$-PUFAs (DHA, EPA and ALA) were not as large as coefficients for egg production rates. 

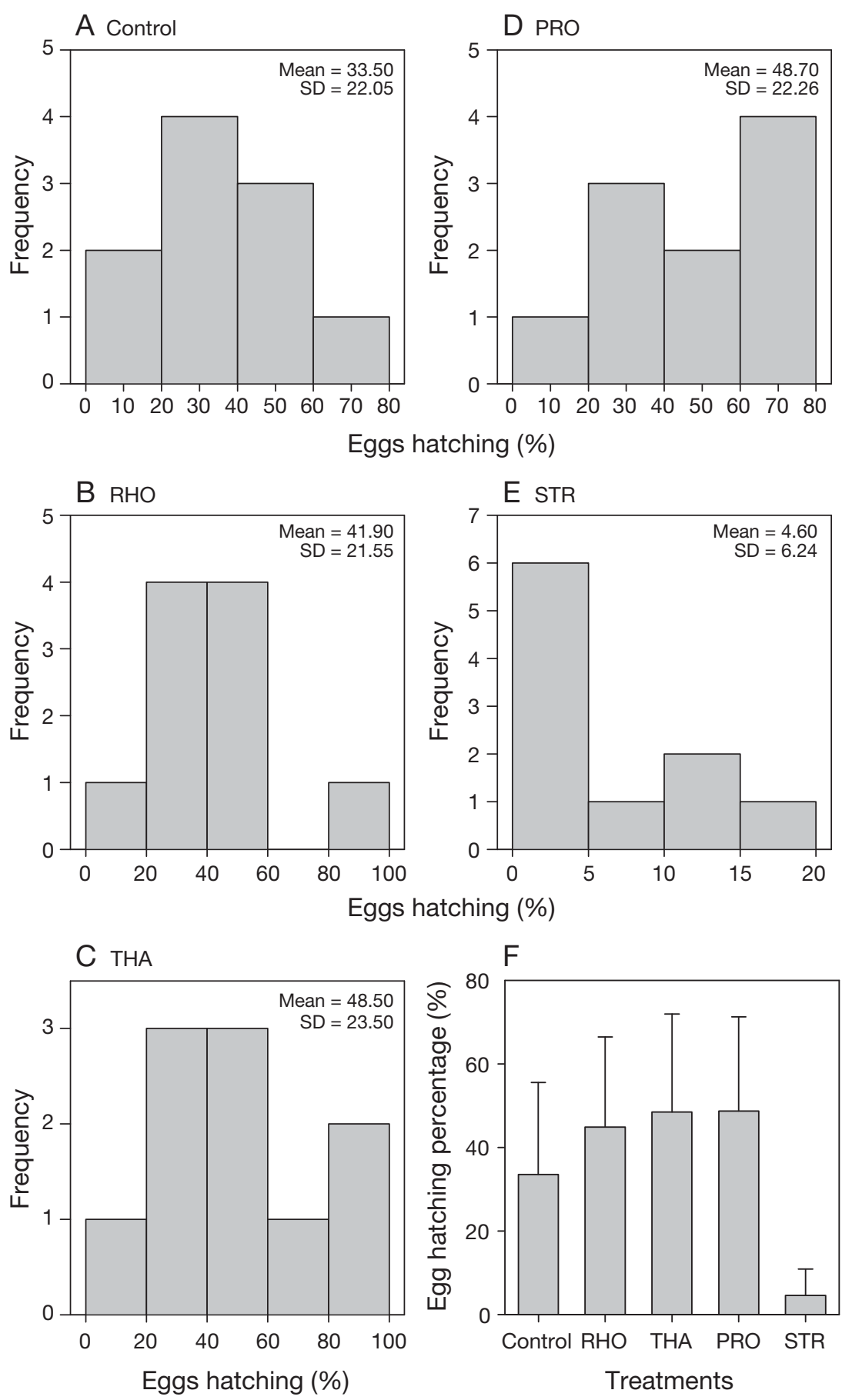

Fig. 6. Acartia erythraea. (A-E) Frequency of eggs hatching during the experiments. (F) Summary of mean percentage and standard deviation. The number of replicates is 10 for all treatments. Treatments combined Dunaliella sp. with either Rhodomonas sp. (RHO), Thalassiosira weissflogii (THA), Prorocentrum dentatum (PRO) or Strombidium sulcatum (STR)

We used the GAM test to further compare partial effects of percentages of DHA, EPA, ALA and $\omega 6-$ PUFAs in total ingested fatty acids, as well as the partial effect of nitrogen/carbon ratio (Table 7). Consistent with the correlation analysis, all $3 \omega 3$-PUFAs had positive partial effects on egg hatching percentage, while the partial effects of $\omega 6$-PUFAs and the $\mathrm{N}: \mathrm{C}$ ratio were minor (Fig. 7). Results indicated that Model 2 including DHA, EPA and ALA as predictors was the best model. Based on deviance explained and the $F$ value, the most important diet component was DHA, while ALA and EPA ranked second and third.

\section{DISCUSSION}

We have shown that different nutritional quality in terms of fatty acid composition in laboratory food environments can create significantly different reproduction rates of the subtropical calanoid copepod Acartia erythraea. These results support an earlier suggestion that at higher water temperatures assimilated food was turned over rapidly and stored lipids were not important (Kattner \& Hagen 2009), so that in the present experiments the responses of the copepods was primarily due to experimental diets.

The egg hatching percentages that we observed, even in treatments with high-quality food, were somewhat lower than in other studies with longer incubation times ( 72 to $96 \mathrm{~h}$ ) at lower temperatures. Limitation of other nutrients such as sterols, which we did not measure, may be one of the reasons (Ederington et al. 1995). Other factors including production of diapause eggs, ages of females, egg incubation time (Sullivan \& McManus 1986, Ianora et al. 1996, CastroLongoria \& Williams 1999) and high variability of the small data set can also be factors that contributed to the low hatching percentage. Nevertheless, eggs hatch quickly at high temperatures, and a comparable pattern of hatching percentages was detected for copepods fed different diets (Ambler 1985, Holste \& Peck 2006). We kept track of the unhatched eggs for several days following each experiment and found that some eggs disappeared, while other eggs decom- 
Table 7. Effects of food composition on egg hatching success revealed by generalized additive models (GAMs). The relative goodness of fit of a model is indicated by the generalized cross validation (GCV) and Akaike information criterion (AIC). Spline (s) in all models is the smooth function, while b is the constant. The deviance of egg hatching success explained by predictors involved is also shown. The best fitting model with the lowest GCV and AIC is shown in bold. Relative strengths of individual predictors in a model are compared by $F$ value and significance $(p)$. The predictor with the smallest explained $F$ value among all predictors in a previous model is reduced in the next model. ns: not significant; DHA: docosahexaenoic acid; EPA: eicosapentaenoic acid; ALA: alpha-linolenic acid; $\sum \omega 6$ : sum of $\omega 6$-fatty acids

\begin{tabular}{|c|c|c|c|c|c|c|c|}
\hline Model & & GCV score & AIC & Deviance explained (\%) & Predictors & $F$ & $\mathrm{p}$ \\
\hline \multicolumn{8}{|l|}{ Full model } \\
\hline \multirow[t]{5}{*}{ Arcsine hatching $=$} & $\mathrm{s}(\mathrm{DHA})+\mathrm{s}(\mathrm{EPA})$ & 450.7 & 448.9 & 42.4 & $\mathrm{~s}$ (DHA) & 5.2 & 0.03 \\
\hline & $+\mathrm{s}(\mathrm{ALA})+\mathrm{s}\left(\sum \omega 6\right)$ & & & & $\mathrm{s}(\mathrm{EPA})$ & 2.6 & $\mathrm{~ns}$ \\
\hline & $+\mathrm{s}(\mathrm{N} / \mathrm{C}$ ratio $)+\mathrm{b}$ & & & & s(ALA) & 2.7 & $\mathrm{~ns}$ \\
\hline & & & & & $\mathrm{s}\left(\sum \omega 6\right)$ & 0.1 & $\mathrm{~ns}$ \\
\hline & & & & & $\mathrm{s}(\mathrm{N} / \mathrm{C}$ ratio $)$ & 2.0 & ns \\
\hline \multicolumn{8}{|l|}{ Model 1} \\
\hline \multirow[t]{4}{*}{ Arcsine hatching $=$} & $\mathrm{s}(\mathrm{DHA})+\mathrm{s}(\mathrm{EPA})$ & 450.7 & 448.9 & 42.4 & $\mathrm{~s}(\mathrm{DHA})$ & 5.4 & 0.025 \\
\hline & $+\mathrm{s}(\mathrm{ALA})+\mathrm{s}\left(\sum \omega 6\right)$ & & & & $\mathrm{s}(\mathrm{EPA})$ & 7.6 & 0.008 \\
\hline & $+\mathrm{s}(\mathrm{N} / \mathrm{C}$ ratio $)+\mathrm{b}$ & & & & $\mathrm{s}(\mathrm{ALA})$ & 3.0 & ns \\
\hline & & & & & $\mathrm{s}(\mathrm{N} / \mathrm{C}$ ratio $)$ & 0.1 & ns \\
\hline \multicolumn{8}{|l|}{ Model 2} \\
\hline \multirow[t]{3}{*}{ Arcsine hatching $=$} & $s(\mathrm{DHA})+\mathrm{s}(\mathrm{EPA})$ & 432.5 & 447.0 & 42.2 & $\mathrm{~s}(\mathrm{DHA})$ & 22.3 & $<0.001$ \\
\hline & $+\mathrm{s}(\mathrm{ALA})+\mathrm{b}$ & & & & $\mathrm{s}(\mathrm{EPA})$ & 9.7 & 0.003 \\
\hline & & & & & $\mathrm{s}(\mathrm{ALA})$ & 11.8 & 0.001 \\
\hline \multicolumn{8}{|l|}{ Model 3} \\
\hline \multirow[t]{2}{*}{ Arcsine hatching $=$} & $s(\mathrm{DHA})+\mathrm{s}(\mathrm{ALA})+\mathrm{b}$ & 437.2 & 447.6 & 41.3 & $\mathrm{~s}(\mathrm{DHA})$ & 19.5 & $<0.001$ \\
\hline & & & & & $\mathrm{s}(\mathrm{ALA})$ & 11.1 & $<0.001$ \\
\hline \multicolumn{8}{|l|}{ Model 4} \\
\hline Arcsine hatching $=$ & $s(\mathrm{DHA})+\mathrm{b}$ & 511.5 & 455.6 & 28.4 & $\mathrm{~s}(\mathrm{DHA})$ & 8.2 & $<0.001$ \\
\hline
\end{tabular}
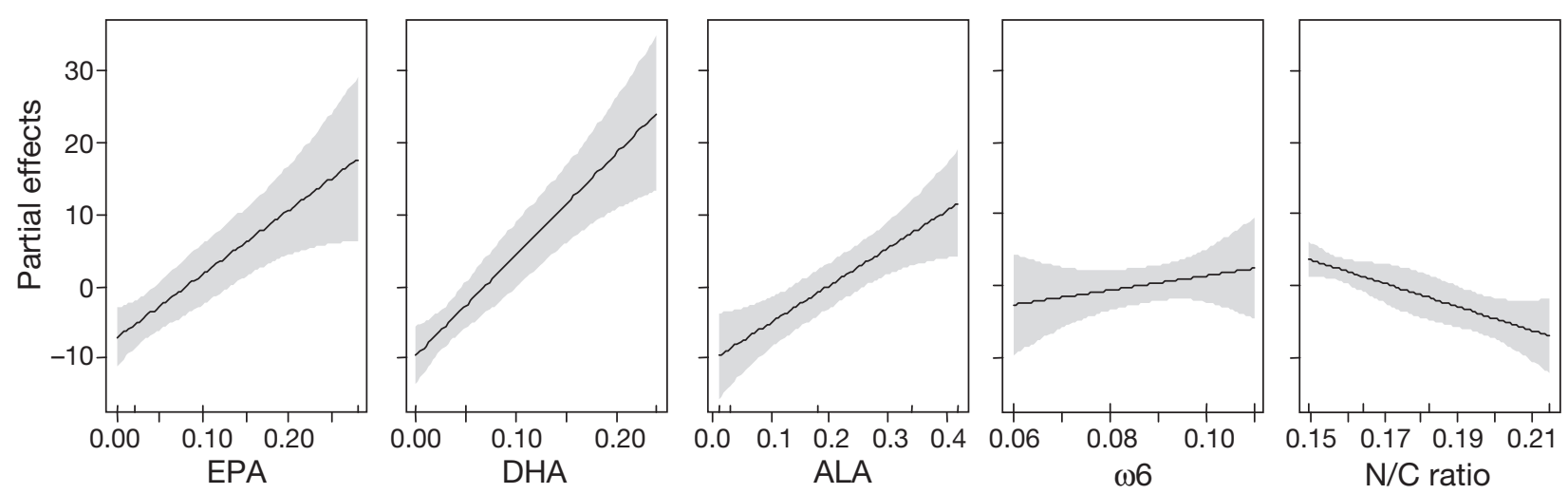

Fig. 7. Partial effects of predictors on variations of egg hatching percentage using predictors including the percentage of alpha-linolenic acid (ALA), eicosapentaenoic acid (EPA), docosahexaenoic acid (DHA) and total $\omega 6$ polyunsaturated fatty acids, and the ratio of nitrogen to carbon. The smoothes of partial effects of predictors are shown as the black line, with the $95 \%$ CI (shading)

posed or hatched unsuccessfully to abnormal forms. This indicated that the eggs were not viable, suggesting that hatching success was primarily affected by the quality of diet in our study rather than by hatching time or production of diapause eggs.

Our GAM test demonstrated that food quality, including both ingested fatty acids and nitrogen, significantly increased the explanation of deviance of egg production rates compared with food quantity (ingested total carbon) alone. Specifically, egg production rates were more closely related to PUFAs than MUFAs and SAFAs, indicating the essential role of PUFAs for the success of copepod reproduction. This result confirms the findings of most copepod food quality studies (Støttrup \& Jensen 1990, Jónasdóttir 1994, Broglio et al. 2003, Arendt et al. 2005, Evjemo et al. 2008, Jónasdóttir et al. 2009). However, there were marked differences in the requirements 
of copepods for $\omega 3$ - and $\omega 6$-PUFAs according to different correlation coefficients (Table 5, Fig. 5), probably due to their different functions in the physiological aspect of reproduction. $\omega 3$-PUFAs are thought to be an important constituent of cell membranes (Parrish 2009). It is likely that adult females will allocate such fatty acids from their diet into egg yolk lipovitellins as much as possible to enhance egg production. By comparison, the main function of $\omega 6-$ PUFAs is to serve as precursors of bioactive signaling compounds such as hormone-like eicosanoids (Ahlgren et al. 2009). As the 2 groups of PUFAs compete for similar enzymes during incorporation and elongation, a balanced ratio is required for copepod hatching success (Ahlgren et al. 2009). A potential suppression of the effects of $\omega 3$-PUFAs may happen when $\omega 6$-PUFAs are obtained in excess. This phenomenon was observed in the STR treatment, where LIN (18:2 $\omega 6)$ was abundant in the ciliate diet, shown by its negative partial effects on egg production rates and egg hatching success (Table 6). Because of competition for $\Delta 6$ desaturase during PUFA synthesis by the abundant LIN (Dalsgaard et al. 2003), the role of ALA as a precursor in synthesizing long-chain PUFAs was constrained.

Our finding that ingested PUFAs serve as an indicator of food quality and together with ingested total carbon as an indicator of food quantity are important for egg production is consistent with similar egg production experiments done by Jónasdóttir et al. (2009) for Temora longicornis. Furthermore, egg production rates of Acartia erythraea were influenced by more than 1 specific fatty acid, especially the long-chain PUFAs such as EPA and DHA. However, Jónasdóttir et al. (2009) suggested that EPA was more important than the other specific fatty acids for $T$. longicornis, and egg production rates were found to be highest in the diatom treatment. This was somewhat different from our results; we found that the autotrophic dinoflagellate Prorocentrum dentatum was the most suitable prey for egg production of $A$. erythraea. Statistical analysis revealed that the high quality of Prorocentrum for $A$. erythraea reproduction can be attributed to its high content of DHA, a specific longchain $\omega 3$ unsaturated fatty acid. Other dinoflagellate species, especially heterotrophic ones that are able to elongate short-chain fatty acids, are also rich in DHA, and have been reported to significantly enhance both growth and reproduction of copepods (KleinBreteler et al. 1999, Tang \& Taal 2005). In a field study, Evjemo et al. (2008) showed that food seston composed of DHA-containing dinoflagellates also supported high egg production rates of $T$. longicor- nis. High nutritional quality of the non-toxic autotrophic dinoflagellates has also been reported for other copepod species in the laboratory (Ianora \& Poulet 1993, Lacoste et al. 2001), and this may reflect an effect of DHA. At the present time, different requirements of copepods for EPA and DHA remain unclear. They may reflect species-specific differences or simply be due to the feeding history of the species.

Of the 5 species used in this study, the diatom Thalassiosira weissflogii and the cryptophyte Rhodomonas sp. have also been regarded as high-quality food for Acartia species and are frequently used in laboratory studies due to their high contents of EPA (Støttrup \& Jensen 1990, Jónasdóttir 1994, Milione \& Zeng 2007). However, we demonstrated that they both supported significantly lower egg production rates than DHA-rich dinoflagellates. Correlation analysis also showed that dietary EPA explained less variation in egg production rates than did dietary DHA (Table 6). The similar egg production rates of copepods in the RHO and THA treatments were consistent with their similar ingestion of DHA (Figs. 3C \& 4), although ingestion of EPA was significantly higher in the THA treatment, suggesting that the intake of EPA was not as critical as DHA. The greater importance of DHA-associated dinoflagellates than EPA-associated diatom and cryptophyte copepod diets can be applied to the coastal environment, where phytoplankton are primarily dominated by diatoms (Liu et al. 2010). In those areas, EPA can be readily obtained by copepods while DHA is limited. Our result corroborates the findings of field investigations which showed that copepod-dominated mesozooplankton strongly selected autotrophic dinoflagellates (Liu et al. 2010).

The bacteria-fed ciliate Strombidium sulcatum resulted in the lowest egg production rate and egg hatching percentage for copepods, suggesting that this particular ciliate species was poor in nutritional quality for copepod reproduction. This finding is in line with the idea that the lack of essential fatty acids or other nutritional biochemical compounds (such as sterols) makes bacteria-fed ciliates a low-quality food for copepod reproduction (Ederington et al. 1995, Broglio et al. 2003). For example, Ederington et al. (1995) reported that the egg production rates of Acartia tonsa fed bacterivorous ciliates were 10 -fold lower than those fed a diatom diet. The importance of ciliates or the definition of ciliate food quality, however, depends on the growing environment of the ciliates provided to the copepods. It has been suggested that the fatty acid profiles of ciliates generally reflect the 
fatty acid composition of their food with little or no modification. Bacteria are characterized as poor in $\omega 3-P U F A s$ and therefore bacteria-fed ciliates are also poor in $\omega 3$-PUFAs (Dalsgaard et al. 2003), which resulted in low egg production rates in previous studies (e.g. Ederington et al. 1995, Broglio et al. 2003) and in the present study. Ciliates can contain high percentages of PUFAs if grown on algae rich in PUFAs. Broglio et al. (2003) reported that S. sulcatum grown on algae contained significantly higher longchain unsaturated fatty acids than the same species grown on bacteria, and consequently resulted in higher copepod egg production rates. Dutz \& Peters (2008) also reported that the reproduction of Acartia clausi could benefit from feeding on ciliates which were grown from previous diatom blooms. The ability of ciliates to elongate short-chain fatty acids is unclear, but particular ciliates such as $S$. sulcatum probably have the ability to elongate ALA to EPA, as suggested by Broglio et al. (2003). If this is the case, the amounts of PUFAs or HUFAs in copepod ingestion from the STR treatment in this study could be somewhat underestimated, as the ciliates ingested by copepods probably contained a certain amount of HUFAs by elongating ALA from the Dunaliella sp. they ingested. However, even if the ability of fatty acid elongation did exist, given the low egg production rates and hatching success, we speculate that the effectiveness of fatty acid elongation was extremely low and was not enough to change the quality of ciliates. Klein-Breteler et al. (2004) clearly indicated in the laboratory that there was no evidence for the ability of trophic upgrading by $S$. sulcatum, similar to our observations. Nevertheless, given the facts that the food source of ciliates in field conditions is diverse and the ciliate feeding spectrum is broad, the fatty acid profiles of bacteria-fed ciliates in laboratory studies probably do not represent the situation in nature. It is likely that the fatty acid composition will be more complex and the nutritional value will be higher for ciliates in nature.

The relative nutritional quality of ciliates also depends on nutritional requirements of the copepods, which could vary with specific environments and development stages. It has been suggested that larval copepods need to obtain as much nitrogen as possible from diets to develop (Jones et al. 2002, KleinBreteler et al. 2005), while adults require just a critical amount of nitrogen to maintain basic metabolism (Anderson \& Hessen 1995). Ciliates have lower C:N ratios compared to many algal prey, which could be very important for copepods if the copepods were surviving in environments that were overall limited by nitrogen or deficient in essential amino acids (Kleppel et al. 1998). Our model test confirmed that nitrogen should be included in the models to explain the deviance of egg production rates, but the partial effect of nitrogen was much smaller than ingested PUFAs, and the removal of nitrogen from model 2 to model 3 caused only a slight decrease of deviance explained (Table 5). Therefore, it seems that the nitrogen requirement for Acartia erythraea was not as critical as PUFAs, and the low C:N ratio in the ciliate Strombidium sulcatum could not compensate for the deficiency of essential PUFAs, especially DHA. Furthermore, we also found that the partial effect of $\mathrm{C} / \mathrm{N}$ ratio was not significant on egg hatching success (Table 7, Fig. 7), which is in agreement with the conclusion that stoichiometric ratios may not reveal food quality among interspecific prey for copepod reproduction (Anderson \& Pond 2000, Broglio et al. 2003).

The egg hatching percentage was reduced by the supplement of ciliates compared to the control diet. The high content of short-chain $\omega 3$ unsaturated fatty acid (ALA) in Dunaliella sp. present with the ciliates was probably important for maintaining a low level of egg production as indicated by a significant correlation (Table 6). ALA appeared to be the only essential fatty acid responsible for the observed hatching success in the control. However, the hatching percentage was significantly lower than in those treatments (RHO, THA and PRO) where EPA and DHA were present. A similar result where Dunaliella supported a low but detectable egg production and hatching success has also been reported in laboratory observations for other copepod species (Støttrup \& Jensen 1990, Lacoste et al. 2001, Arendt et al. 2005). Lacoste et al. (2001) suggested that ALA may act as precursor for EPA or DHA and was elongated by the copepods during fatty acid assimilation. In that case, the quality of the control algae was even higher than the ciliates in terms of providing essential fatty acid precursors. However, clearance and ingestion rates indicated an apparent feeding preference on Strombidium culcatum over Dunaliella sp. The reason for this selectivity is likely related to prey size and mobility (Kiørboe et al. 1996). Such passively selective feeding behaviour (e.g. size selectivity) guarantees a significantly high ingestion of both carbon and nitrogen for the copepods, which ensures that copepods meet the metabolic requirements for basic elements (Rollwagen-Bollens \& Penry 2003). In the mono-diet control, low egg production rates can be due to combined limitation of both basic elements $(\mathrm{C}, \mathrm{N})$ and essential long-chain fatty acids. As the ingestion of total fatty acids was always associated 
with the ingestion of total carbon (Fig. 2), food availability affected the acquisition of total fatty acids. Thus, low carbon intake affected copepod basic requirements of total carbon and resulted in a low allocation of specific fatty acids to reproductive activity (cf. Figs. 2 \& 4). A similar result was also reported by Jónasdóttir et al. (2009), where a mono-algal diet of Dunaliella tertriolecta limited the reproduction of Temora longicornis due to a low daily ration of copepods feeding on the algae independent of the availability of the algae.

DHA and EPA appeared to play an equally important role in egg hatching of Acartia erythraea as there were similar egg hatching percentages in the THA and PRO treatments, although the THA treatment provided a high proportion of EPA in the diet while the PRO treatment provided a high proportion of DHA. However, some studies have suggested that DHA may be more important than EPA because of a positive correlation between egg viability and the DHA:EPA ratio (Shin et al. 2003, Arendt et al. 2005, Peters et al. 2007). We believe that one of the factors that influence the uncertainty of the DHA:EPA ratio as an indicator of food quality for egg hatching is temperature. In cold water, copepods and other marine invertebrates generally require a high DHA:EPA ratio, with the extra DHA from the diet increasing the cell membrane fluidity so as to withstand low temperature (Kattner \&Hagen 2009, Parrish 2009). Different requirements for DHA at different temperatures were demonstrated in a laboratory study where lowering the temperature resulted in the copepods incorporating a higher amount of DHA relative to EPA from their diet (Nanton \& Castell 1999). Because temperature was high in our experiments reflecting the local subtropical and tropical conditions, the requirement for DHA for egg hatching was not as strong as in studies carried out in regions with relatively low temperatures.

In conclusion, our results on dietary fatty acid composition and its relationship with egg production rate and egg hatching percentage support the idea that non-toxic dinoflagellates are superior food items relative to bacterivorous ciliates, because of their high contents of various long-chain unsaturated fatty acids. Field studies have shown low copepod egg hatching success during diatom blooms and high naupliar recruitment rates in post-bloom conditions when phytoplankton was dominated by dinoflagellates and other small flagellates (Miralto et al. 2003). Results from our study in the Hong Kong coastal waters showed that copepods selectively ingested dinoflagellates both during diatom blooms and dur- ing the post-bloom period (Liu et al. 2010), suggesting that copepods strategically obtain more prey with high contents of $\omega 3$ unsaturated fatty acids from diet, especially the fatty acid DHA to maximize reproduction rates. However, the requirements for specific fatty acids or nitrogen depend on the quality and quantity of the prey community in different marine environments.

Acknowledgements. Financial support for this research was provided by the University Grants Committee of Hong Kong's AoE project (AoE/P-04/04), Hong Kong Research Grants Council's (RGC) GRF grants (661809 and 661610) and TUYF Charitable Trust (TUYF10SC08). B.C. was supported by Fundamental Research Funds for the Central Universities (2011121007) of Xiamen University. We thank C. Li for assistance with fatty acid analysis. Comments from the editor and 3 anonymous reviewers significantly improved the quality of the manuscript.

\section{LITERATURE CITED}

Ahlgren G, Vrede T, Goedkoop W (2009) Fatty acid ratios in freshwater fish, zooplankton and zoobenthos: Are there specific optima? In: Arts MT, Brett MT, Kainz MJ (eds) Lipids in aquatic ecosystems. Springer-Verlag, New York, NY, p 147-178

Ambler JW (1985) Seasonal factors affecting egg production and viability of eggs of Acartia tonsa Dana from East Lagoon, Galveston, Texas. Estuar Coast Shelf Sci 20: 743-760

Anderson TR, Hessen DO (1995) Carbon or nitrogen limitation in marine copepods. J Plankton Res 17:317-331

> Anderson TR, Pond DW (2000) Stoichiometric theory extended to micronutrients: comparison of the roles of essential fatty acids, carbon, and nitrogen in the nutrition of marine copepods. Limnol Oceanogr 45:1162-1167

Arendt KE, Jónasdóttir SH, Hansen PJ, Gärtner S (2005) Effects of dietary fatty acids on the reproductive success of the calanoid copepod Temora longicornis. Mar Biol 146:513-530

Bell MV, Dick JR, Anderson TR, Pond D (2007) Application of liposome and stable isotope tracer techniques to study polyunsaturated fatty acid biosynthesis in marine zooplankton. J Plankton Res 29:417-422

> Brett MT, Müller-Navarra DC (1997) The role of highly unsaturated fatty acids in aquatic foodweb processes. Freshw Biol 38:483-499

> Broglio E, Jonasdottir SH, Calbet A, Jakobsen HH, Saiz E (2003) Effect of heterotrophic versus autotrophic food on feeding and reproduction of the calanoid copepod Acartia tonsa: relationship with prey fatty acid composition. Aquat Microb Ecol 31:267-278

> Castro-Longoria E, Williams JA (1999) The production of subitaneous and diapause eggs: a reproductive strategy for Acartia bifilosa (Copepoda: Calanoida) in Southampton Water, UK. J Plankton Res 21:65-84

> Checkley DM (1980) The egg production of a marine plantonic copepod in relation to its food supply: laboratory studies. Limnol Oceanogr 25:430-446

> Dalsgaard J, St John M, Kattner G, Müller-Navarra D, Hagen W (2003) Fatty acid trophic markers in the pelagic marine environment. Adv Mar Biol 46:225-340 
Dutz J, Peters J (2008) Importance and nutritional value of large ciliates for the reproduction of Acartia clausi during the post spring-bloom period in the North Sea. Aquat Microb Ecol 50:261-277

Ederington MC, McManus GB, Harvey HR (1995) Trophic transfer of fatty acids, sterols, and a triterpenoid alcohol between bacteria, a ciliate, and the copepod Acartia tonsa. Limnol Oceanogr 40:860-867

Evjemo JO, Tokle N, Vadstein O, Olsen Y (2008) Effect of essential dietary fatty acids on egg production and hatching success of the marine copepod Temora longicornis. J Exp Mar Biol Ecol 365:31-37

> Fessenden L, Cowles TR (1994) Copepod predation on phagotrophic ciliates in Oregon coastal waters. Mar Ecol Prog Ser 107:103-111

Folch J, Lees M, Sloane-Stanley GH (1957) A simple method for the isolation and purification of total lipids from animal tissues. J Biol Chem 226:497-509

Frost BW (1972) Effects of size and concentration of food particles on the feeding behavior of the marine planktonic copepod Calanus pacificus. Limnol Oceanogr 17: 805-815

Gifford DJ, Dagg MJ (1988) Feeding of the estuarine copepod Acartia tonsa Dana: carnivory vs. herbivory in natural microplankton assemblages. Bull Mar Sci 43: $458-468$

> Guisande C, Riveiro I, Maneiro I (2000) Comparisons among the amino acid composition of females, eggs and food to determine the relative importance of food quantity and food quality to copepod reproduction. Mar Ecol Prog Ser 202:135-142

Harrison KE (1990) The role of nutrition in maturation, reproduction and embryonic development of decapod crustaceans: a review. J Shellfish Res 9:1-28

> Hassett RP (2004) Supplementation of a diatom diet with cholesterol can enhance copepod egg-production rates. Limnol Oceanogr 49:488-494

> Holste L, Peck MA (2006) The effects of temperature and salinity on egg production and hatching success of Baltic Acartia tonsa (Copepoda: Calanoida): a laboratory investigation. Mar Biol 148:1061-1070

- Ianora A, Poulet SA (1993) Egg viability in the copepod Temora stylifera. Limnol Oceanogr 38:1615-1626

Ianora A, Poulet SA, Miralto A, Grottoli R (1996) The diatom Thalassiosira rotula affects reproductive success in the copepod Acartia clausi. Mar Biol 125:279-286

> Jónasdóttir SH (1994) Effects of food quality on the reproductive success of Acartia tonsa and Acartia hudsonica: laboratory observations. Mar Biol 121:67-81

> Jónasdóttir SH, Visser A, Jespersen C (2009) Assessing the role of food quality in the production and hatching of Temora longicornis eggs. Mar Ecol Prog Ser 382: $139-150$

Jones RH, Flynn KJ, Anderson TR (2002) Effect of food quality on carbon and nitrogen growth efficiency in the copepod Acartia tonsa. Mar Ecol Prog Ser 235:147-156

Kattner G, Fricke HSG (1986) Simple gas-liquid chromatographic method for the simultaneous determination of fatty acids and alcohols in wax esters of marine organisms. J Chromatogr A 361:263-268

Kattner G, Hagen W (2009) Lipids in marine copepods: latitudinal characteristics and perspective to global warming. In: Arts MT, Brett MT, Kainz MJ (eds) Lipids in aquatic ecosystems. Springer-Verlag, New York, NY, p 257-280
Kattner G, Hagen W, Lee RF, Campbell R and others (2007) Perspectives on marine zooplankton lipids. Can J Fish Aquat Sci 64:1628-1639

> Kiørboe T, Saiz E, Viitasalo M (1996) Prey switching behaviour in the planktonic copepod Acartia tonsa. Mar Ecol Prog Ser 143:65-75

> Klein-Breteler WCM, Schogt N, Baas M, Schouten S, Kraay GW (1999) Trophic upgrading of food quality by protozoans enhancing copepod growth: role of essential lipids. Mar Biol 135:191-198

Klein-Breteler WCM, Koski M, Rampen S (2004) Role of essential lipids in copepod nutrition: no evidence for trophic upgrading of food quality by a marine ciliate. Mar Ecol Prog Ser 274:199-208

- Klein-Breteler WCM, Schogt N, Rampen S (2005) Effect of diatom nutrient limitation on copepod development: role of essential lipids. Mar Ecol Prog Ser 291:125-133

- Kleppel GS (1993) On the diets of calanoid copepods. Mar Ecol Prog Ser 99:183-195

- Kleppel GS, Holliday DV, Pieper RE (1991) Trophic interactions between copepods and microplankton: a question about the role of diatoms. Limnol Oceanogr 36:172-178

Kleppel GS, Burkart CA, Houchin L (1998) Nutrition and the regulation of egg production in the calanoid copepod Acartia tonsa. Limnol Oceanogr 43:1000-1007

> Lacoste A, Poulet SA, Cueff A, Kattner G, Ianora A, Laabir $M$ (2001) New evidence of the copepod maternal food effects on reproduction. J Exp Mar Biol Ecol 259:85-107

Liu H, Dagg MJ, Strom S (2005) Grazing by the calanoid copepod Neocalanus cristatus on the microbial food web in the coastal Gulf of Alaska. J Plankton Res 27:647-662

Liu H, Chen M, Suzuki K, Wong CK, Chen B (2010) Mesozooplankton selective feeding in subtropical coastal waters as revealed by HPLC pigment analysis. Mar Ecol Prog Ser 407:111-123

Milione M, Zeng C (2007) The effects of algal diets on population growth and egg hatching success of the tropical calanoid copepod, Acartia sinjiensis. Aquaculture 273: 656-664

> Miralto A, Guglielmo L, Zagami G, Buttino I, Granata A, Ianora A (2003) Inhibition of population growth in the copepods Acartia clausi and Calanus helgolandicus during diatom blooms. Mar Ecol Prog Ser 254:253-268

Müller-Navarra DC, Brett MT, Liston AM, Goldman CR (2000) A highly unsaturated fatty acid predicts carbon transfer between primary producers and consumers. Nature 403:74-77

> Nanton DA, Castell JD (1999) The effects of temperature and dietary fatty acids on the fatty acid composition of harpacticoid copepods, for use as a live food for marine fish larvae. Aquaculture 175:167-181

- Nejstgaard JC, Naustvoll L, Sazhin A (2001) Correcting for underestimation of microzooplankton grazing in bottle incubation experiments with mesozooplankton. Mar Ecol Prog Ser 221:59-75

Parrish CC (2009) Essential fatty acids in aquatic food webs. In: Arts MT, Brett MT, Kainz MJ (eds) Lipids in aquatic ecosystems. Springer-Verlag, New York, NY, p 309-326

Persson J, Vrede T (2006) Polyunsaturated fatty acids in zooplankton: variation due to taxonomy and trophic position. Freshw Biol 51:887-900

Peters J, Dutz J, Hagen W (2007) Role of essential fatty acids on the reproductive success of the copepod Temora longicornis in the North Sea. Mar Ecol Prog Ser 341: 153-163 
Rollwagen-Bollens GC, Penry DL (2003) Feeding dynamics of Acartia spp. copepods in a large, temperate estuary (San Francisco Bay, CA). Mar Ecol Prog Ser 257:139-158

Sargent JR, Falk-Petersen S (1988) The lipid biochemistry of calanoid copepods. Hydrobiologia 167-168:101-114

Shin K, Jang M, Jang P, Ju S, Lee T, Chang M (2003) Influence of food quality on egg production and viability of the marine planktonic copepod Acartia omorii. Prog Oceanogr 57:265-277

Stoecker DK, Capuzzo JMD (1990) Predation on protozoa: its importance to zooplankton. J Plankton Res 12: 891-908

Støttrup JG, Jensen J (1990) Influence of algal diet on feeding and egg production of the calanoid copepod Acartia tonsa Dana. J Exp Mar Biol Ecol 141:87-105

Editorial responsibility: Edward Durbin, Narragansett, Rhode Island, USA
Sullivan BK, McManus LT (1986) Factors controlling seasonal succession of the copepods Acartia hudsonica and A. tonsa in Narragansett Bay, Rhode Island: temperature and resting egg production. Mar Ecol Prog Ser 28: 121-128

Tang K, Taal M (2005) Trophic modification of food quality by heterotrophic protists: species-specific effects on copepod egg production and egg hatching. J Exp Mar Biol Ecol 318:85-98

Vargas CA, Escribano R, Poulet S (2006) Phytoplankton food quality determines time window for successful zooplankton reproductive pulses. Ecology 87:2992-2999

Zhukova N, Aizdaicher NA (1995) Fatty acid composition of 15 species of marine microalgae. Phytochemistry 39: 351-356

Submitted: March 16, 2011; Accepted: February 22, 2012 Proofs received from author(s): April 30, 2012 